\title{
LA BARRERA LEGAL EN LAS ELECCIONES AL CONGRESO DE LOS DIPUTADOS Y SU POSIBLE REFORMA
}

\author{
JOAN OLIVER ARAUJO \\ Catedrático de Derecho Constitucional \\ Universidad de las Islas Baleares
}

TRC, núm. 45, 2020, pp. 233-259

ISSN 1139-5583

\section{SUMARIO}

I. La barrera electoral: guillotina de los pequeños. II. La barrera establecida para las elecciones al Congreso de los Diputados. III. Las propuestas de reforma de la barrera legal en las elecciones al Congreso de los Diputados.

\section{LA BARRERA ELECTORAL: GUILLOTINA DE LOS PEQUEÑOS}

\section{Concepto, naturaleza jurídica y finalidad de las barreras electorales}

Las denominaciones «barrera electoral», «barrera legal», «cláusula de exclusión» o «tope electoral» se utilizan, indistintamente, para designar aquellas cláusulas en virtud de las cuales se establece el porcentaje mínimo de votos que debe lograr una candidatura (esto es, una lista electoral) para participar en la distribución de los escaños que están en disputa ${ }^{1}$. En palabras de Ríos Rull ${ }^{2}$, podemos definir la barrera electoral como «aquel límite, impuesto por la legislación electoral, establecido en un determinado porcentaje de votos que impide a las candidaturas que no lo superen el acceso al reparto de escaños, según el modo de escrutinio proporcional adoptado». Dicho en otros términos, es un número mínimo de votos que

1 Cfr. Álvarez Conde, E. y García Couso, S.: «La barrera electoral», Revista de Derecho Político, no 52, 2001, esp. pp. 182-184

2 Cfr. Ríos Rull, F.: «Barreras de exclusión en los sistemas electorales de las Comunidades Autónomas», IV Jornadas de Derecho Parlamentario: reflexiones sobre el régimen electoral, Congreso de los Diputados, Madrid, 1997, pp. 721 y $727-728$. 
deben superar las candidaturas, que concurren a unas elecciones con criterios de reparto proporcional, para poder participar en el reparto de escaños, «de tal manera que, de no alcanzar aquel número de sufragios exigido, queda excluida de la representación, aun cuando según la fórmula electoral» —y de no existir dicha cláusula - tuviera derecho a la adjudicación de uno o varios escaños. Como ha señalado sintéticamente el Tribunal Constitucional ${ }^{3}$, por barrera electoral debe entenderse «la fijación normativa de un determinado porcentaje de sufragios para acceder a la fase de distribución o adjudicación de escaños».

La barrera electoral, por su propia esencia y naturaleza, divide las candidaturas concurrentes en dos grupos: las que superan el porcentaje de votos que aquella exige, que son tomadas en consideración para el posterior reparto de escaños; y las candidaturas que no logran superar la barrera, que no son tomadas en consideración para dicha distribución. Es una diferencia de trato «lesiva para los intereses de los candidatos minoritarios, que se ven privados de acceder a la representación al ser privados de la fase de asignación de escaños». La diferencia de trato, como se ha subrayado ${ }^{4}$, «consiste en la exclusión de los pequeños, de quienes son menos votados, precisamente porque lo son», y esta exclusión supone, y no puede dejar de suponer, un «resultado peyorativo para el sujeto que la sufre, que ve limitados sus derechos o sus legítimas expectativas $»^{5}$.

Los destinatarios de la barrera electoral son, como vemos, los partidos pequeños, pues la mera incorporación al ordenamiento jurídico de esta cláusula de exclusión desalienta su concurrencia a los comicios y, caso de concurrir, condiciona el ánimo con que abordarán la campaña electoral que precede a la votación, al sentir aquella cláusula como una enorme losa que pesa sobre ellos, que difícilmente podrán levantar. Además, es muy posible que los potenciales votantes de estas formaciones políticas pequeñas se dejen seducir por las llamadas, que hacen los partidos grandes, al «voto útil» o que ellos mismos decidan hacer un «voto estratégico» ${ }^{6}$. Con gran fuerza expresiva, el profesor Martínez Sospedra ${ }^{7}$ afirma que si se aplicara a los partidos políticos la legislación sobre la competencia que se aplica a las sociedades mercantiles, «es muy probable que la calificación de un instituto como la barrera electoral oscilara entre el "abuso de posición dominante" y las "prácticas restrictivas de la competencia". Lo primero porque la barrera es sostenida por los partidos grandes contra los pequeños, en cuyo perjuicio opera por razones obvias; lo segundo porque, al tener el efecto señalado en el

3 STC 197/2014, de 4 de diciembre, FJ $7^{\circ}$.c; y STC 15/2015, de 5 de febrero. FJ $8^{\circ}$.a.

4 Cfr. Martínez Sospedra, M.: «Las cláusulas de barrera en la jurisprudencia del Tribunal Constitucional», Revista General de Derecho, no 678-679, 2001, pp. 1.917-1.920 y 1.949-1.950.

5 STC 173/1994, de 7 de junio, FJ. $3^{\circ}$.

6 Sobre el voto estratégico entre nosotros, cfr. LAGo PEÑas, I.: El voto estratégico en las elecciones generales en España (1977-2000). Efectos y mecanismos causales en la explicación del comportamiento electoral, CIS, Madrid, 2005.

7 Cfr. Martínez Sospedra, M.: «Las cláusulas...», op. cit., p. 1.955. 
apartado anterior, erosiona la posición de los partidos menores que no tengan la certeza de superar la barrera en el ámbito en el que se aplica e impide el acceso al "mercado político" de "empresarios" nuevos. Si se desea abandonar esa terminología — sigue afirmando el profesor Martínez Sospedra_, podríamos afirmar que la barrera restringe la competencia política potencial $-\mathrm{y}$, mediante ella, minora la actual — al dificultar la introducción de nuevos actores en el área de competencia política efectiva». Además, no puede olvidarse que somete a una constante inseguridad a aquellos partidos que, aunque normalmente superan la barrera electoral, están muy cerca de ella, lo que fragiliza su imagen y debilita sus expectativas, siempre al albur de algún pequeño cambio en los vientos electorales.

Por efecto de las barreras, los sistemas electorales que incorporan dichas cláusulas — antes de aplicar la fórmula electoral a los resultados producidos- excluyen del reparto de escaños a aquellos partidos que no han logrado superar un número mínimo de voto (los «partidos astillas», en la terminología de Loewens$\left.\operatorname{tein}^{8}\right)$. Las barreras electorales, como hemos visto, «van dirigidas a limitar el acceso de listas de candidatos al reparto de escaños si no han superado un número de votos predeterminado. Por ello, las barreras otorgan la idoneidad a las listas de candidatos para acceder al reparto de escaños» ${ }^{9}$. Con una "claridad no exenta de crueldad», tanto el artículo 163.1.a de la LOREG como el artículo 180 de la misma norma afirman que «no se tienen en cuenta» o «no son tenidas en cuenta» (es decir, que son despreciadas) aquellas candidaturas que no alcancen, al menos, la cuota electoral mínima establecida ${ }^{10}$. Ello, en lógica consecuencia, beneficia a los partidos ya consolidados y al mantenimiento del statu quo.

Con la introducción de una barrera electoral se persigue, como se ha señalado reiteradamente, limitar y racionalizar el número de partidos con acceso al Parlamento, al objeto de evitar su excesiva fragmentación ${ }^{11}$ y, de esta manera, poder formar — sin grandes dificultades - un Gobierno estable y eficaz ${ }^{12}$ (lo que resulta más difícil de lograr cuando este necesita del apoyo de varios partidos políticos para poder aprobar sus propuestas en el Parlamento). En este sentido, los profesores De Esteban Alonso y López Guerra ${ }^{13}$ afirman que las barreras electorales son «dispositivos correctores» del excesivo fraccionamiento partidista, el profesor

8 Cfr. Loewenstein, K.: Teoría de la Constitución, Ariel, Barcelona, 1977, p. 341.

9 Cfr. Ríos Rull, F.: «Barreras...», op. cit., p. 727 (la cursiva es nuestra).

10 Cfr. Martínez Sospedra, M.: «La sombra de las political questions. Notas críticas sobre las STC 197/2014 y 15/2015 sobre las normas electorales para la elección de las Cortes de Castilla-La Mancha», Corts. Anuario de Derecho Parlamentario, $\mathrm{n}^{\circ} 28,2015$, p. 97.

11 Dicho con palabras del profesor I. LAGo PeÑas (El voto..., op. cit., p. 27), «los sistemas electorales tienen efectos — reductores — sobre la competición partidista» cuando se establecen «explícitamente altas barreras de entrada o exigentes umbrales legales».

12 Cfr. López Aguilar, J. F. y García Mahamut, R.: «El nuevo Estatuto de Autonomía de Canarias: "tercera generación”. Hecho diferencial y nuevo sistema electoral», REDC, no 115, 2019, p. 36.

13 Cfr. De Esteban Alonso, J. y López Guerra, L.: «Entre la Ley para la Reforma Política y la Ley Electoral: Análisis del referéndum de diciembre de 1976», El proceso electoral (director: J. de Esteban Alonso), Labor, Barcelona, 1977, p. 375. 
López Aguilar ${ }^{14}$ subraya que combaten la «excesiva atomización de la representación», los profesores Álvarez Conde y García Couso ${ }^{15}$ ponen de relieve que atenúan la proporcionalidad y, en fin, el profesor Sierra Rodríguez ${ }^{16}$ indica que favorecen «la gobernabilidad pese a reducir la representación de las minorías». A modo de ejemplo ilustrativo, podemos recordar que Polonia estableció una exigente barrera electoral tras comprobar que «el sistema proporcional empleado en 1991, en la primera fase de la transición desde el comunismo a la democracia, abrió el acceso a treinta partidos a la Asamblea. Tras establecer una barrera del cinco por ciento de los votos nacionales a los partidos que se presentasen solos y del ocho por ciento a los partidos que se coaligaran, el número de partidos electos cayó a siete en 1993 y a cinco en $1997 »^{17}$.

La doctrina alemana «reconoce que, en interés de la formación de Parlamentos eficaces y de posiciones gubernamentales estables, es lícita la lucha contra la atomización de partidos mediante las llamadas «cláusulas de cierre» (Sperrklauseln) $»^{18}$. No hay duda, en este sentido, de que «las elecciones cumplen la función de proveer al Estado de órganos capaces de actuar; es decir, de un Parlamento que sea capaz, por existir una mayoría, de formar un Gobierno y de realizar una tarea legislativa ${ }^{19}$. Por ello, junto a la lógica aspiración de que la influencia de cada ciudadano sobre los órganos representativos sea lo más igual posible, no se puede olvidar otra aspiración igualmente legítima: que «la influencia de la totalidad de los electores sobre la dirección del Estado, especialmente sobre la formación del Gobierno, sea lo más enérgica posible» ${ }^{20}$.

Se ha afirmado, con razón, que las barreras cumplen «una finalidad directamente desproporcionalizadora del resultado global de la elección» ${ }^{21}$, además de ser un instituto «antipluralista» ${ }^{22}$. Las expresiones italianas «soglia minima di esclu-

14 Cfr. López Aguilar, J. F.: «Los problemas de constitucionalidad del sistema electoral autonómico canario: la insoportable permanencia de una disposición transitoria», REDC, $\mathrm{n}^{\circ}$ 51, 1997, p. 106.

15 Cfr. Álvarez Conde, E. y García Couso, S.: «La barrera...», op. cit., p. 183.

16 Cfr. Sierra Rodríguez, J.: El sistema electoral de la Región de Murcia: regulación, balance (1983-2015) $y$ perspectivas, Universidad de Murcia-Dykinson, Madrid, 2017, p. 121.

17 Cfr. Sodaro, M. J.: Política y Ciencia Política: Una introducción, McGraw-Hill, Madrid, 2006, p. 161 . $52-53$.

18 Cfr. Maunz, T., Dürig, G. y Herzog, R.: Grundgesetz Kommentar, C. H. Beck, Múnich, 1979, pp.

19 Cfr. Trujillo Fernández, G.: «El Estado y las Comunidades Autónomas ante la exigencia constitucional del voto igual», REDC, $\mathrm{n}^{\circ} 2,1981$, p. 25.

20 Cfr. Stein, E.: Derecho Político, Aguilar, Madrid, 1973, p. 45. En el mismo sentido, cfr. TrujiLlo FERnÁNDEZ, G.: «El Estado...», op. cit., p. 25.

21 «Las llamadas barreras mínimas de votos establecidas en algunos sistemas electorales tienen como objetivo excluir del reparto de escaños a los partidos que no las rebasen. Por tanto, tienen una finalidad directamente desproporcionalizadora del resultado global de la elección (...). Lógicamente, cuanto más elevada sea la barrera, mayor será el número de votos inútiles en el reparto de escaños, con la consiguiente deformación de la proporcionalidad». Cfr. Vallès Casadevall, J. M. y Bosch Gardella, A.: Sistemas electorales y gobierno representativo, Ariel, Barcelona, 1997, pp. 143-144.

22 Cfr. Martínez Sospedra, M.: «Las cláusulas...», op. cit., p. 1.945. 
sione» ${ }^{23} \mathrm{y}$ «clausola di sbarramento» resultan muy expresivas de lo que pretende el legislador al introducir las barreras electorales. Con ellas se persigue lograr la estabilidad gubernamental a costa de cerrar la entrada al Parlamento a minorías que «pudieran fragmentarlo» excesivamente ${ }^{24}$. Se trata, sin duda, de una forma muy eficaz de cercenar la proporcionalidad, pues, al margen del efecto objetivo de dejar fuera del reparto a los partidos pequeños (aquellos que no logran superar un determinado porcentaje de votos), produce el efecto psicológico de incitar al electorado a votar a los partidos grandes o medianos, para evitar que su voto «se pierda». Ciertamente, la exigencia de un porcentaje mínimo de votos para poder entrar en el reparto de escaños produce un efecto concentrador, al desincentivar el sufragio a aquellos partidos con escasas o nulas posibilidades de superar la cláusula de exclusión.

El Tribunal Constitucional Federal alemán ${ }^{25}$, de forma pedagógica, ha subrayado que la barrera electoral responde a criterios básicamente funcionales, esto es, al propósito de que el Bundestag pueda trabajar de forma razonable, evitando la entrada en el mismo de pequeños partidos (Splitterparteien), cuya presencia podría ser disfuncional para el sistema ${ }^{26}$. Se trata, en síntesis, de lograr que la proporcionalidad electoral sea compatible con una democracia operativa ${ }^{27}$. En la misma línea, el Tribunal Constitucional español considera que las barreras electorales - a pesar de que, indudablemente, reducen la pluralidad política y limitan el carácter proporcional del escrutinio- son, dentro de ciertos límites, compatible con un sistema electoral proporcional (que es el que exige imperativamente la Constitución para el Congreso de los Diputados — art. 68.3 - y para las Asambleas Legislativas autonómicas —art. 152.1-). En efecto, a juicio de nuestro Tribunal Constitucional ${ }^{28}$, la finalidad de las barreras es procurar «que la proporcionalidad electoral sea compatible con el resultado de que la representación de los electores en tales Cámaras no sea en exceso fragmentaria, quedando encomendada a las formaciones políticas de cierta relevancia». Se trata — sigue argumentando el Tribunal Constitucional en otra sentencia posterior ${ }^{29}$ - «de restricciones a la proporcionalidad, en favor de criterios favorables a la funcionalidad del sistema de gobierno, como pueden ser favorecer la gobernabilidad, evi-

23 Cfr. Rauti, A.: I sistemi elettorali dopo la sentenza costituzionale n. 1 del 2014. Problemi e prospettive, Università degli Studi Mediterranea di Reggio Calabria-Edizioni Scientifiche Italiane, Nápoles, 2014, p. 50.

24 Cfr. Álvarez Conde, E. y García Couso, S.: «La barrera...», op. cit., p. 183.

25 BVerfGE 6, 104,115, 120; 14, 121, 135; 24, 300, 341; 51, 222, 236.

26 Como pone de relieve el profesor O. SÁNCHEZ MuÑOZ ( «Sistema electoral y principio de igualdad del sufragio", Parlamento y sistema electoral. VI Jornadas de la Asociación Española de Letrados de Parlamentos —coordinador: F. Pau i Vall—, Aranzadi, Pamplona, 1999, p. 518), la experiencia de la República de Weimar «ha influido decisivamente» tanto en el legislador como en el Tribunal Constitucional Federal alemanes. Recordemos que, en sus años de existencia (1919-1933), tuvieron lugar seis nuevas elecciones del Reichstag y se constituyeron dieciséis Gobiernos distintos.

27 BVerfGE 1, 208, 247.

28 STC 75/1985, de 21 de junio, FFJJ $4^{\circ}$ y $5^{\circ}$.

29 STC 193/1989, de 16 de noviembre, FJ $4^{\circ}$. 
tar la fragmentación de la representación» o «facilitar la capacidad de trabajo» del Parlamento.

\section{La diferencia entre la «barrera electoral»y el «umbral electoral»}

Como decíamos anteriormente, cualquier partido político que supere la barrera electoral tiene posibilidades legales de obtener alguno de los escaños que se disputan en la circunscripción; cuestión distinta es que lo obtenga realmente, lo que ya dependerá del número de votos obtenidos. Por ello, cercano al concepto de «barrera electoral» - $\mathrm{y}$, en ocasiones, confundido con él- se encuentra el que parte de la doctrina y el propio Tribunal Constitucional denominan «umbral electoral». Este, que es un número de facto no de iure, puede definirse como el porcentaje mínimo de votos necesario para obtener efectivamente, al menos, uno de los escaños que están en liza en la circunscripción. Mientras que «la barrera electoral impide el acceso de la candidatura a la fase de distribución de escaños, el umbral permite que la candidatura acceda, pero le sitúa en la posición de quien, accediendo a la fase de asignación de escaños, carece de posibilidad de alcanzar alguno». En tanto que la barrera electoral es «siempre expresa, el umbral es siempre tácito» ${ }^{30}$. En tanto que la barrera electoral se sabe exactamente cuál es antes de las elecciones (pues viene fijada normativamente), el umbral electoral solo se puede calcular a priori de forma aproximada o hipotética (pues dependerá, además de factores fijos — como la magnitud de la circunscripción y la fórmula proporcional empleada-, de factores variables - como el número de partidos políticos que se presenten a los comicios y la aglutinación o dispersión del voto que emitan los electores-). Solo tras la celebración de las elecciones y efectuado el recuento de votos se podrá saber con exactitud cuál ha sido el umbral electoral (es decir, el porcentaje de votos que ha costado realmente el último escaño de los que estaban en disputa en la circunscripción considerada). Todos los sistemas electorales, independientemente de que tengan o no tengan establecidas barreras electorales, tienen umbrales para lograr representación.

Que el umbral electoral depende de varias circunstancias es, como acabamos de indicar, evidente y el Tribunal Constitucional ${ }^{31}$ lo subraya con razón para apoyar su argumentación. Sin embargo, como se ha señalado con acierto ${ }^{32}$, conviene destacar un dato especialmente relevante en este punto: «La constatación de que la variable "tamaño" tiene un rol mucho más importante que los demás elementos a la hora de determinar el umbral de exclusión en un determinado distrito. La mera alegación según la cual el umbral depende de la interacción entre diversos componentes del

30 Cfr. Martínez Sospedra, M.: «La sombra...», op. cit., p. 98. En el mismo sentido, cfr. Díaz Revorio, J.: «¿Reformar nuestra ley electoral?», La Tribuna de Toledo, 31 de mayo de 2019 (accesible en web https://javierdiazrevorio.com/reformar-nuestra-ley-electoral/).

31 STC 197/2014, cit., FJ $7^{\circ}$.a; STC 15/2015, cit., FJ $8^{\circ}$.

32 Cfr. Martínez Sospedra, M.: «La sombra...», op. cit., p. 98. 
sistema en nada obsta a que entre ellos "el tamaño" desempeña, con mucho, el papel principal». Cuanto menor sea la circunscripción, mayor será el umbral electoral y, viceversa, cuando mayor sea la magnitud del distrito (esto es, el número de diputados que elige) menor será el umbral electoral. Si todos los otros elementos del sistema permanecen inalterados, el umbral será bajo cuando el número de escaños a repartir sea alto y, cuando estos disminuyan, el umbral irá incrementando su dureza.

\section{Las barreras electorales en el Derecho español}

El ordenamiento jurídico estatal y los ordenamientos jurídicos autonómicos han previsto la utilización de barreras de exclusión en todas las elecciones que utilizan un sistema de reparto de escaños de carácter proporcional (con la única excepción de los comicios para elegir diputados al Parlamento Europeo). Por tanto, con voluntad enumerativa, podemos afirmar que, en el Derecho español, se utilizan cláusulas de exclusión en las elecciones al Congreso de los Diputados, en las elecciones a los diecisiete Parlamentos autonómicos y en las elecciones a los órganos de gobierno de los entes locales (Ayuntamientos, Cabildos Insulares canarios y Consejos Insulares baleares).

Ante esta amplísima previsión de cláusulas de exclusión en el Derecho electoral español, hay que subrayar que, sin embargo, ninguna de ellas está establecida por la propia Constitución, que — a diferencia de la Ley para la Reforma Política de 1977— nada prevé al respecto. De hecho, durante el proceso constituyente, el tema de las barreras electorales no motivó ninguna enmienda, ni provocó ninguna discusión parlamentaria. Ante el silencio constitucional, han sido la LOREG, las leyes electorales autonómicas ${ }^{33}$ y, en algún caso, los Estatutos de Autonomía las normas que han introducido en nuestro ordenamiento lo que, en cierta ocasión, denominamos la «guillotina de los pequeños» ${ }^{34}$. Se trata, por tanto, de «barreras legales», en ningún caso de «barreras constitucionales», que podrían ser suprimidas, rebajadas o aumentadas (hasta cierto límite) por el mismo legislador, estatal o autonómico. Su incorporación a nuestros procesos electorales debe considerarse, aunque algún autor ha sostenido su radical inconstitucionalidad ${ }^{35}$, una decisión legitima del legislador orgánico o del legislador ordinario competente.

Ante este carácter exclusivamente legal, sorprende que, en los debates parlamentarios que suscitó la aprobación de la LOREG (que consagra las cláusulas de

33 Cfr. Yanes Herreros, A.: «Los sistemas electorales para las Asambleas Legislativas de las Comunidades Autónomas», IV Jornadas de Derecho Parlamentario: reflexiones sobre el régimen electoral, Congreso de los Diputados, Madrid, 1997, p. 542.

34 Cfr. Oliver Araujo, J.: «La barrera electoral o la guillotina dels petits», en el diario Última Hora, día 2 de octubre de 2012. El profesor V. FrANCH i Ferrer («Las cláusulas de barrera del 5 por 100 en algunas Comunidades Autónomas, diez años después", IV Jornadas de Derecho Parlamentario: reflexiones sobre el régimen electoral, Congreso de los Diputados, Madrid, 1997, p. 883) se refiere, en el mismo sentido, al «efecto guillotina» que tiene la cláusula barrera.

35 Cfr. Martínez Sopedra, M.: «Las cláusulas...», op. cit., pp. 1.947-1.948. 
exclusión en las elecciones al Congreso de los Diputados, a los Ayuntamientos y a los Cabildos Insulares canarios), la cuestión de las barreras electorales apenas mereciera la atención de sus señorías. En sentido estricto, solo hemos encontrado dos intervenciones - ciertamente brillantes, aunque con argumentos discutibles- del diputado Juan María Bandrés Molet (de Euskadiko Ezquerra, integrado en el Grupo Mixto) en contra de la introducción de dichas cláusulas de exclusión ${ }^{36}$. La defensa de dicha enmienda era como predicar en el desierto y, como era previsible, fue rechazada por la Cámara ${ }^{37}$ (el mismo diputado Bandrés indicaba, con pesar, que la defendía «con poca ilusión»).

\section{LA BARRERA ESTABLECIDA PARA LAS ELECCIONES AL CONGRESO DE LOS DIPUTADOS}

\section{La barrera del tres por ciento de los votos válidos emitidos en la circunscripción: alcance y efectividad real}

Aprovechando el silencio de la Constitución, que nada dice al respecto, la LOREG — siguiendo el precedente del Real Decreto-ley 20/1977, de 18 de marzo, sobre normas electorales (art. 20.4.b), aprobado al inicio de la Transición Política ${ }^{38}$ - estableció una accesible barrera electoral, concretada en el tres por ciento de los votos válidos emitidos en la circunscripción. En concreto, el artículo 163.1 de la LOREG, al explicar las reglas conforme a las cuales se van a atribuir los escaños en litigo en cada circunscripción en función de los resultados del escrutinio (es decir, la fórmula D'Hondt), incorpora un primer apartado (letra a) con el siguiente tenor: «No se tienen en cuenta aquellas candidaturas que no hubieran obtenido, al menos, el tres por cien de los votos válidos emitidos en la circunscripción». Como hemos visto, durante la tramitación parlamentaria de la LOREG, el mantenimiento de la barrera electoral procedente de la normativa de la Transición apenas motivó debate, a pesar de que se levantaron algunas voces pidiendo su supresión del texto definitivo ${ }^{39}$.

Lo primero que llama la atención de esta cláusula de exclusión es su escasa efectividad territorial. Ciertamente, teniendo en cuenta la pequeña magnitud (es

36 DSCD, II Legislatura, n ${ }^{\circ} 174,5$ de diciembre de 1984, p. 8.066; y n 199, 18 de abril de 1985, pp. 9.172-9.173.

37 Sometidas a votación las enmiendas del Grupo Parlamentario Mixto suscritas por el señor Bandrés, se dio el siguiente resultado: Votos emitidos, 242; a favor, 24; en contra, 217; nulo, uno. DSCD, II Legislatura, $\mathrm{n}^{\circ} 199,18$ de abril de 1985, p. 9.181.

38 Cfr. Araújo Díaz De Terán, M.: «Artículo 163 LOREG», Comentarios a la Ley Orgánica del Régimen Electoral General y a la Ley Orgánica de Referéndum (coordinador: M. Delgado-Iribarren García-Campero), La Ley, Madrid, 2014, pp. 1.379-1.380.

39 Cfr. Vidal Prado, C.: El sistema electoral español: una propuesta de reforma, Método Ediciones, Granada, 1995, p. 162; Álvarez Conde, E. y García Couso, S.: «La barrera...», op. cit., p. 196. 
decir, número de escaños atribuidos) de la inmensa mayoría de las provincias españolas ${ }^{40}$, dicha barrera solo puede tener eficacia de descarte (esto es, de impedir el acceso al Congreso de los Diputados a candidatos a los que les correspondería un escaño por aplicación de la regla D'Hondt) en las provincias de Madrid y Barcelona, pero no en las otras cuarenta y ocho circunscripciones provinciales ${ }^{41}$ ni, por descontado, en las ciudades autónomas de Ceuta y Melilla, donde se utiliza un sistema electoral mayoritario puro $^{42}$. En este sentido, se ha afirmado, certeramente, que esta cláusula de exclusión — del tres por ciento de los votos válidos emitidos en la circunscripción— «resulta prácticamente estéril desde el punto de vista de su incidencia real en la conformación» del Congreso de los Diputados» ${ }^{43}$, puesto que, «excluidas las provincias de Madrid y Barcelona, el

40 En aplicación del artículo 162 de la LOREG, el RD 551/2019, de 24 de septiembre, de disolución del Congreso de los Diputados y del Senado y de convocatoria de elecciones, dispuso que el número de diputados correspondiente a cada circunscripción en las elecciones del día 10 de noviembre de 2019 fuera el siguiente (Boletín Oficial del Estado de 24 de septiembre de 2019): Albacete (4), Alicante (12), Almería (6), Álava (4), Asturias (7), Ávila (3), Badajoz (6), Baleares (8), Barcelona (32), Bizkaia (8), Burgos (4), Cáceres (4), Cádiz (9), Cantabria (5), Castellón/Castelló (5), Ciudad Real (5), Córdoba (6), La Coruña (8), Cuenca (3), Guipuzkoa (6), Girona (6), Granada (7), Guadalajara (3), Huelva (5), Huesca (3), Jaén (5), León (4), Lleida (4), Lugo (4), Madrid (37), Málaga (11), Murcia (10), Navarra (5), Ourense (4), Palencia (3), Las Palmas (8), Pontevedra (7), La Rioja (4), Salamanca (4), Santa Cruz de Tenerife (7), Segovia (3), Sevilla (12), Soria (2), Tarragona (6), Teruel (3), Toledo (6), Valencia (15), Valladolid (5), Zamora (3), Zaragoza (7), Ceuta (1), Melilla (1).

41 Los profesores D. Nohlen y R.-O. SCHultze ( Los efectos del sistema electoral español sobre la relación entre sufragios y escaños. Un estudio con motivo de las elecciones a Cortes de octubre de 1982», REIS, n 30 , 1985 , pp. 182-183), ya en 1985, subrayaban que la barrera del tres por ciento de los votos válidos en la circunscripción, aplicada a las elecciones del Congreso de los Diputados, solo podía incidir «en las circunscripciones electorales grandes, ya que la magnitud de la circunscripción electoral implica ya un límite más alto del que supone la barrera del mínimo electoral, lo cual se cumple, por lo general, para 50 de las 52 circunscripciones en que se divide el país». En el mismo sentido, el profesor F. FERNÁNDEZ SEGADO («El régimen jurídico electoral español», en su obra Estudios de Derecho Electoral, Ediciones Jurídicas, Lima, 1997, pp. 157-159) afirma: «A la vista de cómo se diseña esta "cláusula de exclusión", también conocida como la "cláusula del tres por cien", hemos de convenir en su escasa operatividad como elemento corrector del excesivo fraccionamiento parlamentario. Esta operatividad será ya no mínima, sino que casi podríamos afirmar que nula. [... El El hecho de que esta "barrera legal del tres por cien" opere a nivel de cada circunscripción la convierte en absolutamente inoperante en la casi totalidad de las circunscripciones. Debería de producirse un fenómeno electoral muy poco previsible [...] para que esta barrera pudiera surtir algún efecto práctico, limitado en todo caso a las circunscripciones de tamaño medio-alto» (las cursivas son nuestras). Con análogo criterio, cfr. Satrústegui Gil-Delgado, M.: «La elección de las Cortes Generales», Derecho Constitucional, Tirant lo Blanch, Valencia, 2010, vol. II, p. 40; BAssols COMA, M.: «El sistema electoral español: balance y perspectivas», Parlamento y sistema electoral. VI Jornadas de la Asociación Española de Letrados de Parlamentos (coordinador: F. Pau i Vall), Aranzadi, Pamplona, 1999, p. 38; Montabes PereirA, J.: «Los sistemas electorales en España y sus posibilidades de reforma (respuestas a cuestionario)», Corts. Anuario de Derecho Parlamentario, $\mathrm{n}^{\circ} 8$, 1999, p. 106; Penadés De La Cruz, A.: «El sistema electoral español (1977-1996)», En torno a la democracia en España (editores: J. L. Paniagua Soto y J. C. Monedero Fernández), Tecnos, Madrid, 1999, pp. 297-298; SÁNCHEZ Navarro, Á. J.: Constitución, igualdad y proporcionalidad electoral, CEPC, Madrid, 1998, p. 91.

42 La circunscripción utilizada para elegir 348 de los 350 escaños que integran la Cámara Baja es la provincia. Las poblaciones de Ceuta y Melilla están representadas cada una de ellas por un diputado (artículo 68.2 CE).

43 Cfr. Martínez VÁzquez, F.: «El sistema electoral en las elecciones al Congreso de los Diputados y al Senado y sus posibles reformas», Estado democrático y elecciones libres: cuestiones fundamentales de Derecho electoral (director: F. Pascua Mateo), Civitas-Thomson Reuters, Cizur Menor (Navarra), 2010, p. 244. En el mismo sentido, cuando analiza las propuestas de reforma del sistema electoral del Congreso de los Diputados, 
coste del escaño está muy por encima de este porcentaje» ${ }^{44}$. Como sintetizaba, gráficamente, el profesor Torres del Moral, la barrera del tres por ciento en las elecciones al Congreso de los Diputados no va «a servir de nada, o de casi nada» ${ }^{45}$.

Sobre este punto nadie podía llamarse a engaño, pues, desde los trabajos publicados por Arend Lijphart en la década de los noventa del pasado siglo ${ }^{46}$, sabemos que — como regla general — una barrera electoral del tres por ciento solo es efectiva en una circunscripción que tiene asignados más de veinticuatro escaños. Ello es así porque, con este número de escaños o por debajo de él, a ningún partido con menos del tres por ciento de los votos le correspondería un diputado en el reparto (aun sin existir la barrera electoral). La cifra de la barrera implícita se calcularía con la siguiente fórmula: setenta y cinco dividido por «n» más uno debe ser igual a la barrera establecida, en este caso, a tres $(75 / \mathrm{n}+1=3)$, siendo «n» el número de escaños. Ello significa que, en teoría, una circunscripción de veinticuatro escaños es equivalente a poner una barrera legal del tres por ciento. Si, por el contrario, tenemos una circunscripción que elige veinticinco diputados, la barrera implícita que comporta el número de escaños ya es inferior al tres por ciento $(75 / 25+1=75 / 26=2$ ' $88 \%)$. Por lo tanto, en este último caso la barrera legal sí que tiene un efecto real, pudiendo impedir que un partido político obtenga los escaños que le corresponderían por aplicación de la fórmula proporcional. Por el contrario, si la barrera implícita es igual o mayor que la barrera legal $(3 \%)$, esta última carece de efecto real, pues ningún partido político con un apoyo popular por debajo de la misma sería llamado a ocupar un escaño. Ello ocurriría, con la fórmula indicada, en las circunscripciones que eligen menos de veinticinco diputados.

Como subrayábamos con anterioridad, solo en dos circunscripciones (Madrid, 37 escaños, y Barcelona, 32 escaños) la barrera electoral — del tres por ciento de los votos válidos emitidos en la circunscripción - puede tener eficacia excluyente de algún partido político al que la fórmula D’Hondt le otorgue algún escaño. Circunstancia que se ha confirmado en la práctica. En efecto, analizando las catorce elecciones al Congreso de los Diputados que se han celebrado desde junio de 1977 hasta noviembre de 2019, comprobamos que ha habido un único candidato excluido por aquella barrera electoral cuando, de acuerdo con la formula proporcional utilizada para el reparto de escaños, le correspondía obtenerlo. Nos referimos al cabeza de lista del Centro Democrático y Social (CDS) por la

afirma que la de eliminar la barrera electoral, «en términos reales, dista mucho de tener verdadera incidencia sobre la representación» (p. 249).

44 Cfr. Fernández-Miranda Campoamor, A.: «Reflexiones sobre una improbable reforma del sistema electoral del Congreso de los Diputados», RDP, $\mathrm{n}^{\circ} 74,2009$, p. 24.

45 Cfr. Torres Del Moral, A.: «La reforma del sistema electoral o la cuadratura del círculo», RDP, $\mathrm{n}^{\circ} 74,2009$, p. 61.

46 Cfr. Lijphart, A.: Sistemas electorales y sistemas de partidos: un estudio de veintisiete democracias 19451990, CEC, Madrid, 1995, pp. 63 y sig. (la versión original apareció un año antes en Oxford University Press). 
provincia de Madrid en las elecciones generales celebradas el 6 de junio de 1993, que obtuvo — como veremos, con detalle, en el próximo epígrafe- el 2'97 por ciento de los votos válidos en la circunscripción (93.347), lo que le impidió obtener el escaño que según la fórmula D’Hondt le correspondía.

\section{Consecuencias de la inclusión de los «votos en blanco» dentro de los «votos válidos» para calcular la barrera electoral. Especial referencia al caso Rafael Calvo Ortega}

La cláusula de exclusión establecida en las elecciones al Congreso de los Diputados se calcula sobre los «votos válidos» emitidos (art. 163.1.a LOREG). Pues bien, de conformidad con los artículos 96.5 y 108.4 de la LOREG, son «votos válidos» (únicos que se toman en consideración para calcular la barrera electoral) los votos otorgados a las candidaturas contendientes más los votos en blanco; en cambio, no se incluyen en aquella categoría los «votos nulos». A juicio del Tribunal Constitucional ${ }^{47}$, «en modo alguno puede calificarse de irrazonable o arbitrario el entendimiento de que los votos nulos no hayan de computarse a efectos de determinar el porcentaje de votos que corresponde a cada partido, coalición, federación o agrupación de electores, precisamente a causa de su ineficacia radical». Interpretación que, además, encuentra «apoyatura en el principio general de ineficacia de los actos nulos».

Aclarado este último punto, volvamos a los dos preceptos de la LOREG que acabamos de citar (arts. 96.5 y 108.4). Según su tenor literal, el «voto en blanco» es un «voto válido», considerándose «voto en blanco» el sobre que no contenga papeleta (art. 96.5 LOREG). Sobre la conveniencia o no de incluir dentro de la categoría de «votos válidos» a los «votos en blanco» (lo que endurece levemente la cláusula de exclusión ${ }^{48}$ ), la doctrina se ha mostrado dividida. Así, el profesor Gavara de Cara ${ }^{49}$ parece inclinarse por excluir de esta suma (sobre la que se aplicará el porcentaje de la cláusula de exclusión) los votos en blanco, «ya que su finalidad apartidista no se relaciona con la fragmentación del voto». En sentido opuesto, al principio de la Transición Política (1977), se pronunciaba el profesor Espín Templado ${ }^{50}$, al afirmar

47 STC 185/1999, de 11 de octubre, FJ $3^{\circ}$.

48 Como afirmó el profesor E. EsPin Templado ( «Desarrollo y resultado de la elección», El proceso electoral —director: J. de Esteban Alonso_- Labor, Barcelona, 1977, p. 148), la inclusión de los votos en blanco dentro de los válidos «dificulta la elección, al necesitarse mayor número de votos para alcanzar cualquier porcentaje de votos válidos requeridos, al ser el total de estos más elevado». La diferencia —añadimos nosotrosno es, en todo caso, grande, pues los votos en blanco son un número muy pequeño de los que se depositan en las urnas. Con todo, sí que supone poner un poco más alto el listón que hay que saltar para poder acceder al reparto de escaños.

49 Cfr. Gavara De Cara, J. C.: La homogeneidad de los regímenes electorales autonómicos, CEPC, Madrid, 2007 , p. 249.

50 Cfr. Espín Templado, Eduardo: «Desarrollo...», op. cit., p. 148. 
que el voto en blanco «es una opción que expresa disconformidad, no indiferencia, que lleva más bien al abstencionismo, ni ignorancia del mecanismo electoral, que provoca el voto nulo en sentido estricto (mal emitido)». Y añadía: estimar válidos los votos en blanco «tendría la significación de dar una posibilidad de expresar, de forma mensurable, su descontento a partidos fuera del sistema o contrarios a la votación de que se trate por cualquier circunstancia, sin que se vea envuelta la cifra de votos en blanco en la ambigüedad de una abstención o de los votos nulos».

De hecho, la opción legislativa de incluir o no los votos en blanco dentro de los sufragios válidos y, en consecuencia, de sumarlos o no a los votos otorgados a los partidos políticos contendientes al objeto de determinar — posteriormenteel quantum numérico a que asciende la barrera electoral, no se ha mantenido constante a lo largo de la actual andadura democrática ${ }^{51}$. Sin embargo, tras la aprobación de la LOREG en 1985 y, sobre todo, tras su reforma por la Ley Orgánica 8/1991, de 13 de marzo, la Junta Electoral Central subrayó el cambio normativo producido en este punto. Ciertamente, en aplicación de la Ley Orgánica del Régimen Electoral General (en concreto de su artículo 96.5 — que diferencia netamente los votos nulos de los emitidos en blanco, precisando que los votos en blanco son votos válidos - y de su artículo 108.4 — que afirma literalmente que «se computarán como votos válidos los obtenidos por cada candidatura más los votos en blanco»-), la Junta Electoral Central, entre otros en su Acuerdo de 27 de mayo de 1991, afirmó que los votos válidos son los emitidos en favor de las candidaturas más los votos en blanco. En consecuencia, sostuvo que, «en orden al cálculo de la llamada barrera electoral, han de computarse los votos emitidos en favor de las candidaturas más los votos en blanco, excluyendo únicamente del cómputo a los referidos efectos los votos declarados nulos» ${ }^{52}$. La meridiana claridad de los dos artículos citados de la LOREG no permitía otra interpretación de lege lata que la que ahora realizaba la Junta Electoral Central.

Con todo, y pesar de la referida claridad normativa, el tema llegó hasta el Tribunal Constitucional, en el asunto que finalizó con la Sentencia ${ }^{53}$ que resolvió el recurso de amparo electoral interpuesto por Rafael Calvo Ortega, cabeza de lista del Centro Democrático y Social (CDS) por la provincia de Madrid en las elecciones al Congreso de los Diputados celebradas el 6 de junio de 1993. Los hechos que lo motivaron fueron, en síntesis, los que exponemos a continuación.

- El recurrente había obtenido el 2'97 por ciento de los votos válidos en dicha circunscripción (93.347), lo que le impidió por tres centésimas obtener el escaño que según la fórmula D’Hondt le correspondía. Dicho

51 Cfr. Oliver Araujo, J.: Las barreras electorales. Gobernabilidad versus representatividad, Tirant lo Blanch, Valencia, 2017, p. 78.

52 Acuerdo de la JEC 172/1991, de 27 de mayo.

53 STC 265/1993, de 26 de julio. 
escaño fue asignado a la lista del $\mathrm{PSOE}^{54}$. Esta decisión de la Junta Electoral Provincial de Madrid fue recurrida por Calvo Ortega ante el Tribunal Supremo, por la vía contenciosa-administrativa, y ante el Tribunal Constitucional, a través de un recurso de amparo. Tanto el Tribunal Supremo (Sentencia de 13 de julio de 1993) como el Tribunal Constitucional (Sentencia 265/1993, de 26 de julio de 1993) desestimaron los recursos planteados.

- El argumento del recurrente era, en esencia, que — para el cálculo del tres por ciento de los votos válidos emitidos en la circunscripción- no debian computarse los votos en blanco. Interpretación que, de ser aceptada, hubiera situado al CDS por encima de aquella barrera electoral del tres por ciento y, por tanto, la Junta Electoral le hubiera debido atribuir un escaño. La demanda de amparo constitucional sostiene que la Sentencia del Tribunal Supremo impugnada vulnera los artículos 23.1 y 2 y 24 , así como - por su estrecha conexión con el 23-el 1.1 y 2, 6, 9.2, 10 y 14 de la Constitución. Considera, en primer lugar, que la referida resolución viola el artículo 24 de la CE por falta de motivación suficiente. Para el recurrente, la Sala realiza una interpretación literal, cerrada y hermética de los artículos 96.5 y 108.4 de la LOREG, sin pronunciarse acerca del «ejemplo práctico» contenido en el artículo 163.1, en el que los votos válidos se componen exclusivamente de votos a candidaturas, no siendo posible alegar a estos efectos que en dicha elección no hubo ni un solo voto en blanco. Tampoco se pronuncia sobre el principio de especialidad entre normas del mismo rango legal, el principio de interpretación restrictiva de las normas limitativas de derechos fundamentales, ni sobre la infracción de determinados artículos constitucionales, especialmente del mandato contenido en el artículo 9.2. Por todo ello, considera que la Sentencia impugnada carece de motivación suficiente en términos constitucionales, con vulneración de los artículos 120 y 24 CE. Considera, igualmente, que la Sentencia vulnera el art. 24.1 en cuanto que es irracional, arbitraria o contradictoria, al interpretar erróneamente el artículo 163.1.a de la LOREG, al ponerlo únicamente en relación directa con los arts. 96.5 y 108.4, sin tener en cuenta el apartado «c» del art. 163.1, que se refiere precisamente a las operaciones posteriores al escrutinio general. Ignora, además, en aras a la mera literalidad de los preceptos, el criterio de interpretación más favorable a los derechos fundamentales, que hubiera debido llevar al Tribunal Supremo a interpretar conjuntamente los apartados «a»y «c» del artículo 163.1, en virtud de la recta interpretación de los artículos 23.1 y 2 de la Constitución, que exigen la efectividad del derecho de sufragio

54 Cfr. Torres del Moral, A.: Principios de Derecho Constitucional español, UCM, Madrid, 1998, pp. 
activo y, en consecuencia, de los votos válidos emitidos por el electorado del CDS, y la efectividad del derecho al acceso a los cargos públicos, de forma que, a quien ha obtenido un escaño conforme al resultado electoral, no se le prive del mismo por una interpretación restrictiva de los derechos fundamentales. El recurrente afirma, asimismo, que el cómputo de la barrera legal tal y como se ha efectuado vulnera los artículos 23.1 y 2 de la Constitución, ya que el mantenimiento de la voluntad expresada en votos válidos debe constituir el criterio preferente a la hora de interpretar las normas electorales, y — desde esa perspectiva - resulta claro que, si bien ha de protegerse la voluntad de los electores que han votado en blanco, no cabe hacer depender la eficacia de los votos válidamente emitidos a determinadas candidaturas de los votos emitidos por ciudadanos que lo que desean, en realidad, es «no influir» en el resultado electoral de ninguna de las candidaturas. Por ello, considera que el Tribunal Constitucional debería declarar inconstitucionales los artículos de la LOREG que hagan llegar a tal conclusión. También afirma que serían inconstitucionales por la penalización que sufren los partidos políticos menores, en la medida en que vulnerarían el artículo 9.2 CE. Asimismo, ahora desde la óptica del artículo 23.2 CE, considera que el referido artículo incluye la prohibición de cualquier impedimento al acceso a los cargos públicos que no haya sido legalmente previsto de modo expreso, supuesto que considera aplicable a la inclusión de los votos en blanco dentro del cómputo de la barrera electoral. Por último, señala que la Sentencia impugnada vulnera igualmente los artículos 1.1 y 2, 6, 9.2, 10 y 14 de la Constitución, así como el Convenio Europeo de los Derechos del Hombre, y en concreto el artículo 3 de su Primer Protocolo de 20 de marzo de 1952, al infringir el principio institucional del pluralismo político y el principio de los derechos cívicos, especialmente el derecho al voto y a ser candidato. Concluye la demanda presentada por Calvo Ortega suplicando el otorgamiento del amparo, lo que supondría la declaración de nulidad de la Sentencia del Tribunal Supremo impugnada y del Acuerdo de Proclamación de Electos de la Junta Electoral Provincial de Madrid de 16 de junio de 1993 y, en consecuencia, la proclamación del candidato electo número uno de la lista del CDS, al cumplir el requisito del tres por ciento de votos válidamente emitidos.

- No fue esta, sin embargo, la decisión que adoptó el Tribunal Constitucional, quien consideró que el clarísimo tenor literal de los artículos 96.5 y 108.4 de la LOREG (de conformidad con la redacción que les dio la Ley Orgánica 8/1991, de 13 de marzo) hacía absolutamente rechazable la interpretación de los recurrentes. En efecto, a su entender, «el legislador despejó cualquier posible duda que pudiera presentar la cuestión mediante la nueva redacción dada a los artículos 96.5 y 108.4 por la Ley Orgánica 8/1991, el primero de ellos distinguiendo netamente entre 
voto nulo y voto en blanco, y el segundo estableciendo un específico y terminante mandato a las Juntas Electorales para que computen, a efectos de atribución de escaños, como votos válidos "los obtenidos por cada candidatura más los votos en blanco"». Y añade el Tribunal Constitucional: «Frente a la claridad de estos preceptos comunes no cabe derivar del ejemplo que contiene el artículo 163.1.c de la misma Ley, en el que ciertamente se atribuyen los escaños sin especificar la existencia y el número de los votos en blanco, un mandato legal contradictorio con los artículos anteriores para que las Juntas Electorales no contabilicen los votos en blanco a efectos de la determinación del mínimo exigible. Por el contrario, la finalidad del legislador es únicamente mostrar la forma en que deben atribuirse los escaños de acuerdo con los votos efectivamente obtenidos por cada candidatura, sin hacer referencia a la fase previa del procedimiento en la cual se determina el número de votos válidos según las normas de los artículos 96.5 y 108.4. Por ello, de la no referencia a los votos en blanco en el ejemplo del artículo 163 de la LOREG, no cabe deducir consecuencia normativa alguna ni tampoco la conclusión de que el legislador quisiera excluir los votos en blanco de los votos válidos». Finaliza el Tribunal Constitucional su razonamiento con las siguientes palabras: «No puede estimarse... irrazonable la solución adoptada por el legislador y aplicada por la Sentencia del Tribunal Supremo, consistente en estimar válidos los votos en blanco a efectos de computar el mínimo exigible, puesto que estos suponen una legítima opción política de participación en el proceso electoral. Por ello, reconocida su validez por la Ley no cabe entender que constituya violación del artículo 23 de la Constitución la concreta fórmula de distinguir el voto en blanco del voto nulo» ${ }^{55}$.

\section{Los motivos para introducir una barrera legal «casi» ineficaz}

A raíz de las anteriores reflexiones nos surge un interrogante sobre cuáles eran las intenciones reales del legislador al establecer, para las elecciones al Congreso, la referida barrera electoral del tres por ciento de los votos válidos en la circunscripción. Y decimos que nos surgen dudas porque el legislador no podía desconocer que la cláusula de exclusión que establecía solo podía tener efectos reales en las provincias de Madrid y Barcelona, que superaban ampliamente los veinticinco escaños cada una, en tanto que en las otras cuarenta y ocho provincias 
sería totalmente ineficaz ${ }^{56}$. No olvidemos que, como afirma profesor Remiro Brotóns $^{57}$, si la barrera de exclusión que introduce la legislación electoral «es inferior a la cuota de votos que reclama la obtención de un escaño, parece innecesario mortificar los principios» del sistema proporcional con la introducción de dicha barrera. Repetimos, pues, la pregunta: ¿Cuál es la finalidad que se persigue con aquella cláusula de exclusión?

\section{A) Los motivos durante la Transición Política}

El profesor Torres del Moral $^{58}$ cree que hay que buscar la explicación de aquella norma en nuestra singular Transición Política. En concreto, entiende que es preciso remontarse a las principales normas que la hicieron posible, esto es, a la Ley $1 / 1977$, de 4 de enero, para la Reforma Política (LRP), y al Real Decreto-ley 20/1977, de 18 de marzo, sobre normas electorales, que desarrollaba aquella.

En el otoño de 1976, al discutirse la Ley para la Reforma Política en las Cortes franquistas, la mayoría de los procuradores se inclinaban por un sistema electoral mayoritario frente a un sistema de carácter proporcional. Esta preferencia tenía posiblemente dos causas: una ideológica y otra personal. La primera, porque pensaban que el sistema mayoritario cerraría el paso a gran parte de partidos políticos que concurriesen a las elecciones (recordemos que los procuradores en Cortes habían hecho profesión de fe antipartidista al jurar, solemnemente, los Principios Fundamentales del Movimiento Nacional). La segunda, porque los procuradores que no querían terminar su carrera política con el fin del franquismo tenían la esperanza — surgida de motu proprio o a instancias de voces interesadasde tener «cierto terreno ganado en su futuro distrito» si se establecía un sistema mayoritario ${ }^{59}$. Por el contrario, la oposición democrática y el mismo Gobierno de Adolfo Suárez preferían un sistema electoral proporcional. Aquella porque entendía que la proporcionalidad era sinónimo de justicia («a cada uno lo suyo»), y este para evitar que se reprodujera el enfrentamiento de los españoles en dos bandos irreconciliables. En efecto, el Gobierno del Presidente Suárez también apostaba por un modelo proporcional, aunque fuera atenuado ${ }^{60}$, para evitar que aparecie-

$56 \mathrm{El}$ profesor C. Vidal PRAdo (El sistema electoral español..., op. cit., p. 116) afirma que esta barrera es «innecesaria». Adjetivo que hace más referencia a su conveniencia que a sus efectos prácticos.

57 Cfr. Remiro Brotóns, A.: «La representatividad de la población y de los Estados en el Parlamento Europeo", Parlamento y sistema electoral. VI Jornadas de la Asociación Española de Letrados de Parlamentos (coordinador: F. Pau i Vall), Aranzadi, Pamplona, 1999, p. 347.

58 Cfr. Torres del Moral, A.: «Prólogo» al libro colectivo Análise das eleccións autonómicas galegas do 21 de outubro de 2012. Reflexións sobre o sistema electoral (director: A. Torres del Moral; coordinador: F. Martínez Arriba), Andavira Editora, Santiago de Compostela, 2013, esp. pp. 11-15.

59 Ibídem, p. 12. También, cfr. Vidal Prado, C.: El sistema electoral español..., op. cit., p. 152.

60 «Proporcional, ma non troppo», se dijo en alguna ocasión. 
ran —una vez más — las «dos Españas» contendiendo en frentes antagónicos, que era el resultado previsible de un sistema electoral mayoritario.

Para lograr que los procuradores franquistas cambiaran de criterio y apoyaran la opción electoral proporcional para el Congreso de los Diputados ${ }^{61}$, el Gobierno (además de utilizar otras técnicas menos jurídicas pero no menos eficaces — como prometerles un puesto en los cuarenta senadores de elección real o recordarles que en España funcionaba la Inspección de Hacienda ${ }^{62}$-) hizo especial hincapié en que la elección de las Cortes sería — pese al tenor literal de la LRP $^{63}$ - realmente poco proporcional. En tal sentido, subrayaba que establecía un sistema de escrutinio mayoritario para el Senado (amén de los senadores regios), que fijaba un número de diputados reducido (350), que otorgaba una cuota fija de diputados a cada una de las cincuenta provincias al margen del criterio poblacional, y que —y es lo que ahora nos interesa a nosotros_ introducía una barrera electoral, para dejar fuera del Parlamento a los partidos políticos con escasos apoyos. En concreto, sin esconder en absoluto la carga ideológica que la inspiraba, la disposición transitoria primera de la LRP afirmaba expresamente que se aplicarían «dispositivos correctores para evitar fragmentaciones inconvenientes de la Cámara, a cuyo efecto se fijarán porcentajes mínimos de sufragios para acceder al Congreso» ${ }^{64}$. Este precepto — cuya primera parte era más propia de una exposición de motivos que de un texto articulado — se refería, de forma diáfana, a la necesidad de establecer una barrera electoral para impedir el paso al Congreso de los Diputados a aquellos partidos cuyos resultados estuvieran por debajo de la misma ${ }^{65}$.

61 Como afirma el profesor F. FERnÁNDEZ SEGADo (Aproximación a la nueva normativa electoral, Dykinson, Madrid, 1986, p. 17), «el pacto del Gobierno con los procuradores en Cortes [franquistas] fue inexcusable, pues estaba en juego la propia viabilidad de una reforma profunda dentro del respeto formal de la legalidad vigente; esos condicionamientos con que se lastró la normativa electoral fueron posiblemente el único medio de sacar adelante la Ley para la Reforma Política, pero, es evidente que, en cierto modo, condicionaron el devenir del proceso político subsiguiente».

62 Cfr. Torres Del Moral, A.: «Prólogo» al libro colectivo Análise..., op. cit., pp.12-13.

63 La disposición transitoria primera de la LRP afirmaba lo siguiente: «El Gobierno regulará las primeras elecciones a Cortes para constituir un Congreso de 350 diputados... Las elecciones al Congreso se inspirarán en criterios de representación proporcional...».

64 La disposición transitoria primera de la LRP, tras afirmar que «las elecciones al Congreso se inspirarán en criterios de representación proporcional», añadía: «...conforme a las siguientes bases: Primera. Se aplicarán dispositivos correctores para evitar fragmentaciones inconvenientes de la Cámara, a cuyo efecto se fijarán porcentajes mínimos de sufragios para acceder al Congreso. Segunda. La circunscripción electoral será la provincia, fijándose un número mínimo inicial de diputados para cada una de ellas. Las elecciones al Senado se inspirarán en criterios de escrutinio mayoritario». En un interesante y polémico libro, el profesor J. PÉREZ ROYO (La reforma constitucional inviable, Catarata, Madrid, 2015, p. 105) ha subrayado el dilatado alcance político del contenido de esta disposición transitoria.

65 El profesor A. Torres del Moral («Prólogo» al libro colectivo Análise..., op. cit., p. 13) subraya que, «a la postre, las Cortes orgánicas quedaron doblegadas, como corresponde a una "Cámara de aplauso" propia de un régimen no democrático. Quien está acostumbrado a aplaudir a su jefe, quiere seguir haciéndolo con el nuevo para tenerlo contento y que este lo mantenga en su sinecura». 
Dando cumplimiento al mandato contenido en la LRP ${ }^{66}$, el Gobierno aprobó el Real Decreto-ley 20/1977, de 18 de marzo, sobre normas electorales, que concretaba bastante más los criterios para la elección del primer Congreso de los Diputados tras la dictadura. En concreto, por lo que se refiere a nuestro objeto de estudio, hay que subrayar que su artículo 20.4.b establecía que: no serían «tenidas en cuenta aquellas listas que no hubiesen obtenido, por lo menos, el tres por ciento de los votos válidos emitidos en el distrito». El Preámbulo ${ }^{67}$ de dicho Real Decreto-ley nos explicaba, reiterando la idea expresada en la LRP, la finalidad de dicha cláusula de exclusión, al afirmar que «supone un poderoso corrector del excesivo fraccionamiento de las representaciones parlamentarias».

Como vemos, esta barrera electoral, que apenas podía tener eficacia real, fue presentada ante los procuradores en Cortes franquistas — cuyos conocimientos en materia electoral podemos presumir que eran, en la mayoría de ellos, más bien escasos - como una de las referidas técnicas para impedir la presencia de numerosos partidos en el futuro Congreso de los Diputados («evitar fragmentaciones inconvenientes»). Con ello, el Gobierno de Adolfo Suárez trataba de persuadir a los procuradores franquistas de que todo estaría controlado y de que no se repetiría la atomización partidista de la Segunda República. La existencia de una barrera electoral (como todo lo que podía cercenar la pluralidad partidista) «sonaba bien» a los oídos de unos procuradores en Cortes que, como sabemos, habían jurado lealtad al partido único. Estas razones psicológico-políticas explican, a nuestro juicio, la incorporación de aquella barrera electoral (inane, pero aparente) en la Ley para la Reforma Política.

\section{B) Los motivos durante la democracia consolidada}

Si la barrera del tres por ciento de los votos válidos emitidos en la circunscripción consagrada en la LRP puede explicarse, al menos en parte, por las razones que acabamos de exponer, más difícil resulta comprender por qué motivos la mantuvo la LOREG en 1985 y por qué la mantiene aún en la actualidad (tras las numerosísimas reformas de que ha sido objeto dicha Ley). En sede parlamentaria $^{68}$, se afirmó que «lo hemos hecho porque aumentar este tope supondría eliminar de la Cámara la posibilidad de la presencia de alguno de los grupos pequeños, sean de ámbito nacional o de ámbito de Comunidades Autónomas». Sin despreciar esta argumentación (mantener la barrera en el tres por ciento de los votos

66 La disposición transitoria primera de la LRP establecía, en su inciso inicial, que el Gobierno regularía «las primeras elecciones a Cortes».

67 Preámbulo, apartado IV, párrafo quinto.

68 Cfr. CORTES GENERALES: LOREG. Trabajos Parlamentarios, Publicaciones de las Cortes Generales, Madrid, 1985, p. 8.064 . 
válidos emitidos en la circunscripción para no excluir a las minorías), creemos que la respuesta más concreta debe buscarse en una doble dirección:

a) Por una parte, en la creencia del legislador de que esta cláusula si bien no sirve prácticamente de nada, al ser fundamentalmente «ornamental» ${ }^{69}$, tampoco daña y, sin embargo, sigue siendo una especie de declaración de principios de que los partidos pequeños no son bienvenidos al Parlamento español, al tiempo que implícitamente se les impele a formar grupos políticos más amplios, mediante un procedimiento de agregación de volunta$\operatorname{des}^{70}$. Con criterio análogo, Martínez Vázquez ${ }^{71}$, después de afirmar que la barrera establecida para las elecciones al Congreso es «prácticamente estéril» en cuanto a efectos excluyentes reales, añade: «Otra cosa es el efecto psicológico que la existencia de la citada barrera electoral puede llegar a tener en los electores, en la medida en que apunta claramente hacia la conveniencia del voto útil». En el mismo sentido se expresa el profesor Fernández Segado ${ }^{72}$, al afirmar que una cláusula de esta naturaleza puede surtir efectos «de orden psicológico, retrayendo el voto de un elector proclive a opciones políticas muy minoritarias, y reconduciéndolo hacia otras alternativas. También puede constituir — sigue argumentando el catedrático de la Universidad Complutense - un freno relativo frente a la aparición de nuevas formaciones políticas, al exigir de ellas un mínimo respaldo electoral para poder tener alguna posibilidad» de obtener un escaño.

b) Por otra parte, la inclusión de esta barrera prácticamente ineficaz se explicaría por la conocida tendencia inmovilista del legislador electoral en general y del legislador electoral español en particular (en los últimos cuatro decenios) que, como es sabido, se ha plasmado en que no se ha suprimido ningún elemento electoral de la LRP, salvo, lógicamente, los senadores de designación real. De hecho, la inercia electoral y la resistencia al cambio en esta materia ya fueron puestas de relieve por el profesor Alzaga Villaamil en los debates constituyentes ${ }^{73}$. Con toda razón, el profesor Pérez Royo ${ }^{74}$ ha

69 El profesor A. YANES Herreros («Los sistemas...», op. cit., pp. 53-54), en términos genéricos, se refiere a «la función ornamental de la cláusula de exclusión, cuya incorporación sería resultado más de una reproducción mimética o irreflexiva de una moda que una fundada preocupación para evitar la excesiva fragmentación parlamentaria».

70 En la misma línea de pensamiento, el profesor F. PALlarés PORTA ( «Sistema electoral y sistema de partidos», Parlamento y sistema electoral. VI Jornadas de la Asociación Española de Letrados de Parlamentos - coordinador: F. Pau i Vall—, Aranzadi, Pamplona, 1999, p. 75) afirma que dicha barrera, aunque es prácticamente irrelevante, «es un mecanismo para limitar los incentivos a formar nuevos partidos».

71 Cfr. Martínez VÁzQuez, Francisco: «El sistema...», op. cit., p. 244.

72 Cfr. Fernández Segado, Francisco: «El régimen jurídico...», op. cit., p. 159; Aproximación..., op. cit., pp. 87 y 89 .

73 Diario de Sesiones del Congreso de los Diputados, $\mathrm{n}^{\circ} 108,12$ de julio de 1978, p. 4.183.

74 Cfr. Pérez Royo, J.: La reforma..., op. cit., pp. 58-59. 
subrayado «la continuidad, la casi identidad se podría decir, entre el "bloque normativo" preconstitucional respecto del ejercicio del derecho de sufragio y el "bloque de constitucionalidad" posterior a $1978 \ldots$ que es materialmente el mismo». Ello no debe extrañarnos, ya que - como afirman los profesores Baras Gómez y Botella Corral ${ }^{75}$ — «sería justo decir que el derecho electoral constituye, con mucho, uno de los sectores más conservadores del ordenamiento jurídico. Las leyes electorales se modifican, en lo sustancial, muy poco; y esas modificaciones acostumbran a darse solamente en momentos de graves convulsiones y de cambio de régimen político». Los motivos para este conservadurismo son varios. «En primer lugar, los partidos políticos y los electores se habitúan a un cierto sistema electoral. El cambio requiere adaptarse (modificar estructuras, mecanismos de decisión, etc.), y tanto las organizaciones políticas como los ciudadanos sienten una cierta aversión a adaptarse a condiciones nuevas. En segundo lugar, y es una razón más de fondo, el sistema electoral se establece y se modifica por ley; las leyes las redacta la mayoría parlamentaria; y la mayoría parlamentaria lo ha llegado a ser en virtud de la anterior ley electoral. De tal manera que quienes pueden tener deseos de cambio no tienen los instrumentos políticos para llevarlo a cabo, y quienes tienen los instrumentos frecuentemente no tienen la voluntad». Con su habitual perspicacia, el profesor Fernández-Miranda Campoamor ${ }^{76}$ justifica el carácter conservador del ordenamiento electoral con una argumentación realista y cruda: «Las leyes electorales contribuyeron a hacer mayorías parlamentarias y las mayorías parlamentarias hacen las leyes electorales. Nadie tira piedras contra su propio tejado, contra el instrumento normativo que le ha facilitado, o no le ha impedido, ser mayoría. De aquí que las críticas al sistema electoral sean casi siempre patrimonio de la oposición».

\section{LAS PROPUESTA DE REFORMA DE LA BARRERA LEGAL EN LAS ELECCIONES AL CONGRESO DE LOS DIPUTADOS}

\section{Tres propuestas en la misma dirección: endurecer la barrera}

Este carácter esencialmente coreográfico de la cláusula de exclusión establecida para las elecciones al Congreso de los Diputados ha motivado que - desde los primeros momentos de su vigencia - se hayan levantado voces

75 Cfr. Baras Gómez, M. y Botella Corral, J.: El sistema electoral, Tecnos, Madrid, 1996, pp. 35 y, especialmente, 169-170.

76 Cfr. Fernández-Miranda Campoamor, A.: «Los sistemas electorales para el Congreso de los Diputados y el Senado", IV Jornadas de Derecho Parlamentario: reflexiones sobre el régimen electoral, Congreso de los Diputados, Madrid, 1997, p. 524. 
abogando por su endurecimiento, cambiándola por un tope electoral que tenga, en mayor o menor medida, efectos reales. En esencia, se han formulado tres propuestas en este sentido: primera, elevar la barrera del tres al cinco por ciento de los votos válidos emitidos en la circunscripción; segunda, mantener la barrera en el tres por ciento, pero realizando el cómputo sobre los votos emitidos en todo el Estado; y tercera, la suma de las dos medidas anteriores, esto es, situar la barrera en el cinco por ciento de los votos válidos emitidos en todo el Estado (aunque con cláusulas específicas para los partidos políticos que limitan su actuación a una Comunidad Autónoma concreta). Con frecuencia, el mismo autor ha defendido, como alternativas, dos de las anteriores propuestas, pues el objetivo de todas ellas es el mismo: sustituir la casi «simbólica» barrera establecida en las elecciones al Congreso de los Diputados por otra que, efectivamente, tenga eficacia de exclusión.

\section{Elevar la barrera del tres al cinco por ciento de los votos válidos emitidos en la circunscripción}

La primera propuesta que pretende dar virtualidad a la cláusula de exclusión del Congreso (elevándola hasta el cinco por ciento de los votos válidos emitidos en la circunscripción) ha sido defendida, con matices, por los profesores Arnaldo Alcubilla, Vidal Prado, Fernández Segado y Martínez Cuadrado. En concreto, Arnaldo Alcubilla ${ }^{77}$, tras subrayar que «es perceptible que la barrera electoral establecida por el art. 163.1.a en el tres por ciento de los votos emitidos en la circunscripción no tiene eficacia», considera necesario modificar este parámetro «para provocar una mayor concentración de la representación, mediante su elevación, como en las elecciones locales y en la mayor parte de las autonómicas, al cinco por ciento». También el profesor Vidal Prado ${ }^{78}$ propone dicho incremento porcentual, aunque vinculado a que se utilice la fórmula de reparto electoral del resto mayor. Por su parte, el profesor Fernández Segado ${ }^{79}$ sostiene que (de no aceptarse la propuesta de realizar el cómputo de la barrera a nivel estatal en lugar de provincial) podría experimentarse con otra fórmula alternativa, consistente en «incrementar cuantitativamente el porcentaje exigido, del tres al cinco por ciento, computado a nivel de circunscripción». Considera que, con esta elevación, se podría conseguir «un cierto control» de esta «proliferación» de partidos políticos en el Congreso de los Diputados, al menos en las circunscripciones de Madrid y Barcelona ${ }^{80}$. Por último, el profesor

77 Cfr. Arnaldo Alcubilla, E.: «Los sistemas electorales en España y sus posibilidades de reforma (respuestas a cuestionario)», Corts. Anuario de Derecho Parlamentario, no 8, 1999, p. 34.

78 Cfr. Vidal Prado, C.: El sistema electoral español..., op. cit., p. 243.

79 Cfr. Fernández Segado, F.: Aproximación..., op. cit., p. 90.

80 Ibidem, p. 91. 
Martínez Cuadrado ${ }^{81}$ estima que es «de todo punto necesario elevar» la barrera electoral en el Congreso «al cinco por cien», pues con ello se evitaría «una miríada de representantes únicos de micropartidos», que si bien «pueden caber en una asamblea local, son profundamente perturbadores en tiempos de normalización del sistema democrático y parlamentario de gobierno nacional o central».

De todas maneras, esta primera propuesta — con los datos normativos actuales: una Cámara de 350 diputados y una representación mínima inicial de dos diputados por provincia - solo ampliaría la eficacia de la barrera electoral a la circunscripción de Valencia (que se añadiría a las de Madrid y Barcelona). En efecto, aplicando la fórmula de Arend Lijphart, que ya hemos estudiado con anterioridad, podemos afirmar que una barrera electoral del cinco por ciento solo es efectiva en una circunscripción que tiene asignados más de catorce escaños. Por el contrario, con este número de escaños o por debajo de él, a ningún partido con menos del cinco por ciento de los votos le correspondería un puesto en el reparto que se lleva a cabo con la regla D'Hondt. Por tanto, de conformidad con la distribución de escaños provincial que llevó a cabo el Real Decreto 551/2019, de 24 de septiembre, de disolución del Congreso de los Diputados y del Senado y de convocatoria de elecciones, solo podría resultar afectada la circunscripción de Valencia que eligió quince representantes. Sin embargo, también es preciso subrayar que sería distinto el efecto excluyente si, dentro de los actuales márgenes constitucionales, optáramos por el máximo de proporcionalidad (esto es, un Congreso con cuatrocientos diputados y una representación mínima inicial por circunscripción de un diputado). En este caso, la barrera del cinco por ciento de los votos válidos emitidos podría tener eficacia (esto es, dejar fuera del reparto a partidos que, según la fórmula D’Hondt, deberían obtener representación), además de en Madrid, Barcelona y Valencia, en las provincias de Sevilla, Alicante, Málaga, Murcia y Cádiz.

\section{Elevar la barrera del tres por ciento provincial al tres por ciento estatal}

La segunda propuesta que quiere dar eficacia real a la barrera electoral de la Cámara Baja consiste en mantener el porcentaje de exclusión en el tres por ciento, pero computado no sobre los votos emitidos en la circunscripción electoral (la provincia) sino sobre los votos emitidos en todo el territorio del Estado. Esta propuesta es la defendida, como la mejor opción, por el profesor Fernández Segado ${ }^{82}$. En síntesis, propone la combinación de una barrera mínima en todo el territorio

81 Cfr. Martínez Cuadrado, M.: «Bases, principios y criterios para la reforma de la Ley Electoral de 1977», Revista de Política Comparada, n 6, 1981, p. 40; «Bases, principios y criterios de la reforma electoral española: examen jurídico-constitucional», REP, nº 34, 1983, pp. 55-56.

82 Cfr. Fernández Segado, F.: Aproximación..., op. cit., pp. 89-90. 
estatal con otra más elevada referida solo a una o varias circunscripciones. En concreto, propugna una cláusula de exclusión del «tres por ciento de los votos a nivel nacional con carácter generalizado y, a título de excepción, un porcentaje que podría oscilar entre el diez y el quince por ciento de los votos, computando a nivel autonómico o, simplemente, a nivel del conjunto de circunscripciones en que presentaran candidaturas, fórmula que regiría para aquellos partidos o coaliciones que se presentaran tan solo en un ámbito territorial previamente delimitado; en definitiva, para las formaciones de carácter regional o, si se prefiere, nacionalistas».

Esta propuesta de endurecimiento de la barrera electoral, sin atenuación de ningún tipo, fue la que incluyó el partido político Ciudadanos (C's) en su programa electoral para los comicios generales del 28 de abril de 2019. En efecto, bajo el rótulo «Una Ley Electoral más justa e igualitaria», afirmaba: «Estableceremos el requisito de que los partidos tengan que conseguir como mínimo el tres por ciento del voto nacional para entrar en el Congreso [de los Diputados]». Esta propuesta y otras también en materia electoral se justificaban, con argumentos más políticos que jurídicos, en los siguientes términos: "Reformaremos la Ley Electoral para que sea más justa e igualitaria, para que España no dependa de los que quieren romperla. En Ciudadanos queremos que todos los electores se vean representados en el Congreso y contar con diputados que trabajen por el interés común de toda España, no solo de una parte».

4. Elevar la barrera al cinco por ciento de los votos válidos emitidos en todo el Estado (aunque con cláusulas específicas para los partidos políticos que limitan su actuación a una Comunidad Autónoma concreta)

La tercera propuesta que pretende hacer efectiva la cláusula de exclusión del Congreso (situar la barrera en el cinco por ciento de los votos emitidos en todo el Estado) es, evidentemente, la más dura de las tres, pues, por una parte, eleva el porcentaje de votos exigido (del tres al cinco por ciento) y, por otra, extiende el ámbito territorial de los votos (de provincial a estatal) sobre el que se calculará dicho porcentaje. El profesor Torres del Moral ${ }^{83}$ afirma que, a pesar de que en España ha habido políticos que la han sugerido, la barrera del cinco por ciento de los votos en todo el territorio nacional, le "parece extremadamente injusta». De hecho, la mayoría de los autores que han defendido esta propuesta (conscientes del desastre político que implicaría — para el buen funcionamiento del Estado- dejar fuera del Congreso de los Diputados a los partidos nacionalistas y regionalistas con importante implantación en sus

83 Cfr. Torres Del Moral, A.: «La reforma...», op. cit., p. 103. 
territorios ${ }^{84}$ ) la han matizado. En concreto, subrayan la necesidad imperiosa de que se establecieran las cláusulas precisas para que también estas fuerzas políticas, de amplio apoyo en sus Comunidades pero incapaces de superar una barrera electoral computada a nivel estatal, pudieran tener una representación justa en el Congreso de los Diputados ${ }^{85}$. En este sentido, el profesor López Pina ${ }^{86}$ estimaba que la cláusula de exclusión debe aplicarse como se lleva a cabo en la República Federal Alemana ${ }^{87}$, en atención al importante papel que ha tenido en dicho país en la consolidación del sistema de partidos. El profesor Martínez Cuadrado ${ }^{88}$, por su parte, consideraba también que podría ser conveniente elevar la barrera al cinco por ciento a nivel estatal. Posibilidad que, sin embargo, le llevaba a plantearse inmediatamente qué pasaría, en este supuesto, con los partidos nacionalistas o regionalistas implantados en una sola Comunidad Autónoma. Su razonamiento era del siguiente tenor: «Con un cinco por ciento de umbral nacional, solo las grandes constelaciones nacionales, esto es, las cuatro grandes fuerzas, u otra que sumase tal mínimo, pueden tener acceso

84 «Salvo que, desde una letal ingenuidad, alguien piense que la expulsión de los nacionalismos del sistema... fuera un mecanismo para resolver el grave y secular problema de la articulación territorial del Estado español». Cfr. Fernández-Miranda Campoamor, A.: «Reflexiones...», op. cit., p. 45.

85 Una legislación electoral perfecta desde planteamientos teóricos, pero que marginara a dichas fuerzas políticas, sería una pésima normativa electoral. En efecto, como afirma el profesor A. FERNÁNDEZ-MIRANDA CAMPOAMOR («Los sistemas...», op. cit., p. 532), «puede uno perfectamente prever cuáles hubieran sido las consecuencias de la inexistencia de un Grupo parlamentario catalán o, en su caso, de un Grupo parlamentario vasco... Esto, naturalmente, no nos hubiera conducido a un Estado unitario, sino que lo más probable es que hubiera conducido a convertir a nacionalistas vascos y nacionalistas catalanes en fuerzas antisistema, ante la imposibilidad de integrarse en la estructura del Estado y de condicionar el proceso constituyente que, al fin y al cabo, había de amparar la pretensión histórica hacia la autonomía política».

86 Cfr. López Pina, A.: «Sobre la ley electoral», Sistema: Revista de Ciencias Sociales, n 16, 1977, p. 109.

87 Por lo que se refiere a las elecciones al Bundestag, podemos afirmar que el artículo 6 de la Ley Electoral Federal (Bundeswablgesetz) ha establecido una elevada barrera de exclusión (Sperrklauseln), indicando que puede superarse por dos vías alternativas. En concreto, para que un partido político contendiente en unas elecciones generales tenga derecho a participar en la distribución de escaños, debe cumplir una de estas dos condiciones: obtener, al menos, el cinco por ciento de los segundos votos (a partidos políticos) en el conjunto de la Federación o, alternativamente, haber conseguido, al menos, tres escaños directos a través de los primeros votos (a candidatos individuales) en distritos uninominales. La conveniencia e incluso la constitucionalidad de dicha barrera electoral han provocado numerosas controversias en la doctrina alemana. Sin embargo, Tribunal Constitucional Federal, en reiteradas ocasiones, ha declarado que la barrera electoral del cinco por ciento nacional (complementada con la posibilidad de acceder también al reparto de escaños si se obtienen, al menos, tres mandatos directos) es conforme a la Ley Fundamental, pues respeta el principio de igualdad del sufragio. El argumento para justificar la existencia de la barrera electoral siempre es, desde sus primeras sentencias, el mismo: la necesidad de garantizar que el Parlamento pueda funcionar de una manera razonable. Como ha subrayado la doctrina, en la posición del Tribunal Constitucional Federal favorable a la barrera electoral ha pesado, sin duda, el recuerdo del fracaso final de la República de Weimar (1919-1933). Fracaso que, como es sabido, tuvo su principal causa en el multipartidismo, absolutamente disfuncional, provocado por un sistema electoral proporcional puro, que motivó una marcada ingobernabilidad y facilitó la llegada de Hitler al poder.

88 Cfr. Martínez Cuadrado, M.: «Bases, principios y criterios para la reforma de la Ley Electoral...», op. cit., p. 40; IDEM: «Bases, principios y criterios de la reforma electoral española...», op. cit., p. 56. 
al Congreso. La forma de resolver el umbral nacional y el de Comunidad Autónoma solo puede afrontarse recurriendo al mecanismo de partidos operantes en Comunidad Autónoma, sin voluntad de participar en otras circunscripciones y distritos, y exigiéndoles en tal caso un umbral mínimo del diez por ciento de votos válidos reclutados en la Comunidad Autónoma para acceder al Congreso de Diputados. De todos modos — seguía opinando el profesor Martínez Cuadrado-, sería preciso reforzar la propensión de los partidos nacionalistas a efectuar alianzas con fuerzas nacionales, incitándoles con mecanismos jurídicos y políticos a tales alianzas, y disuadiendo, por procedimientos similares, a su presentación aislada, lo mismo que a las pequeñas formaciones político-electorales locales». Se trataba, sin duda, de una opinión bien intencionada, aunque, si contemplamos lo que ha ocurrido en la realidad política, podemos afirmar que el recorrido de esta propuesta ha sido más bien limitado. Los profesores De Esteban Alonso y López Guerra ${ }^{89}$ defendieron también esta tercera propuesta para dar efectividad a la cláusula de exclusión (situar la barrera en el cinco por ciento de los votos emitidos en todo el Estado), aunque con un planteamiento mucho más generoso hacia los partidos políticos con implantación territorial limitada. En concreto, hace más de cuarenta años (1977), los dos eminentes constitucionalistas escribieron: el porcentaje mínimo de votos para poder acceder al Parlamento «forzosamente, para que tenga sentido, ha de computarse a nivel nacional». Y añadían: «Ahora bien, un porcentaje muy reducido (digamos un 0 ' 5 por cien) sería inefectivo, mientras que un porcentaje muy alto (digamos un 5 por cien)... impediría el acceso al Congreso a los partidos regionales. Si se quiere evitar esto, parece que la solución debería ser [...]: exigir una barrera legal que no se aplicaría a los partidos de las minorías regionales». Y concluían su razonamiento afirmando: «Todo partido que se declarase regional quedaría por tanto exento de tal exigencia de un número mínimo de votos. Lo que podría reforzarse con una prohibición a los partidos regionales de presentar candidatos, por ejemplo, en más de cuatro provincias (ya que el País Vasco -incluyendo Navarra-, Cataluña y Galicia cuentan, respectivamente, con cuatro provincias)».

Esta tercera propuesta de reforma de la barrera electoral del Congreso de los Diputados (concretada, como hemos visto, en situarla en el cinco por ciento de los votos válidos emitidos en todo el Estado) también ha recibido el aplauso de algún periódico de prestigio. Así, el diario $A B C$, en su editorial del día 19 de junio de 1994, afirmaba con vehemencia que «Aznar y González deben ponerse de acuerdo en la reforma de la ley electoral, de manera que, como en Inglaterra o Francia, se garanticen en la medida de lo posible, dentro del juego democrático, mayorías estables para que el Gobierno de la Nación, de la autonomía o del

89 Cfr. De Esteban Alonso, J. y López Guerra, L.: «Entre la Ley...», op. cit., p. 375 (la cursiva es nuestra). 
Ayuntamiento no estén chantajeados por los partidos bisagra. Al Congreso de los Diputados no deben acceder nada más que los partidos políticos que obtengan por encima del cinco por ciento de la votación nacional o, en su defecto, por encima del veinticinco por ciento en su autonomía» ${ }^{90}$.

A nuestro juicio, una barrera electoral del tres o del cinco por ciento en el conjunto del Estado, sin atenuaciones de ningún tipo, no parece compatible con un sistema que — por mandato de la Constitución — debe ser proporcional (art. 68.3) y potenciador del pluralismo político (art. 1.1), pues dejaría fuera del Congreso de los Diputados a todos los partidos nacionalistas (a menos que formasen amplias coaliciones entre ellos ${ }^{91} \mathrm{e}$, incluso, a algunos partidos políticos pequeños (pero no insignificantes) establecidos en el conjunto del Estado ${ }^{92}$. Debemos subrayar, además, que el cálculo de la barrera sobre el conjunto de votos emitidos en todo el territorio que celebra elecciones y no sobre cada concreta circunscripción, aunque ha tenido algún precedente en del Derecho autonómico español (Canarias, Valencia y Murcia), es desconocido en nuestro régimen electoral general.

TITLE: The legal barrier in the elections to the Spanish Lower House ( Congreso de los Diputados») and its possible reform.

ABSTRACT: This paper analyzes the «electoral barrier» or «exclusion clause» established by law for the elections to the Lower House (three percent of the valid votes cast in the constituency). After studying the real scope and effectiveness of this barrier, as well as the consequences of considering «blank votes» as «valid votes», we wonder about the reasons that justified (during the Political Transition) and (currently) still justify the application of an "almost» inefficient electoral barrier. Finally, we analyze the three reform proposals for this clause (so that it is no longer ornamental and becomes discriminatory): first, to raise the barrier from three to five percent of the valid votes cast in the constituency; second, to maintain the barrier at three percent, but by counting votes cast throughout the State; and third, the combination of the two previous measures, that is, to set the barrier at five percent of the valid votes cast throughout the State (although with specific clauses for political parties that limit their performance to a specific autonomous region).

RESUMEN: Este trabajo analiza la «barrera electoral» o «cláusula de exclusión» establecida por ley para las elecciones al Congreso de los Diputados (el tres por ciento de los votos válidos emitidos en la

90 «Aznar-González», p. 29, en la sección «Opinión» (las cursivas son nuestras).

91 La única posibilidad que podrían tener los partidos nacionalistas/independentistas para superar la barrera electoral del cinco por ciento estatal sería formando coaliciones entre ellos. Así, por ejemplo, los partidos políticos integrantes de GALEUSCA (BNG, PNV y CIU) hubieran podido superar aquella cláusula de exclusión. En concreto, en 2008, lo hubieran hecho con un porcentaje estatal de votos del 5'05\%; y en 2011, con un porcentaje del 6.25\%. Muy distinta hubiera sido la situación en las elecciones generales del 20 de diciembre de 2015, en las que aquellos tres partidos, incluso coaligados con otros más pequeños, solo hubieran alcanzado el $373 \%$ estatal.

92 Como nos recuerda la profesora R. García MAHAmut ( «La reforma de los sistemas electorales autonómicos tras las elecciones de 24 de mayo de 2015: vectores jurídicos y políticos», $T R C \mathrm{n}^{\circ} 41,2018$, p. 204), «una barrera electoral excesivamente desmesurada... [acrecienta] la desproporcionalidad desde la perspectiva de la representación política». 
circunscripción). Tras estudiar el alcance y efectividad real de esta barrera, así como las consecuencias de incluir los «votos en blanco» dentro de los «votos válidos», nos preguntamos sobre los motivos que justificaron (durante la Transición Política) y siguen justificando (en la actualidad) la aplicación de una barrera electoral «casi» ineficaz. Por último, analizamos las tres propuestas de reforma de dicha cláusula (para que deje de tener carácter ornamental y pase a tener eficacia excluyente): primera, elevar la barrera del tres al cinco por ciento de los votos válidos emitidos en la circunscripción; segunda, mantener la barrera en el tres por ciento, pero realizando el cómputo sobre los votos emitidos en todo el Estado; y tercera, la suma de las dos medidas anteriores, esto es, situar la barrera en el cinco por ciento de los votos válidos emitidos en todo el Estado (aunque con cláusulas específicas para los partidos politicos que limitan su actuación a una Comunidad Autónoma concreta).

KEY WORDS: Electoral barrier, electoral exclusion clause, Congreso de los Diputados, electoral barrier reform, electoral system.

Palabras Clave: Barrera electoral, cláusula de exclusión electoral, Congreso de los Diputados, reforma de la barrera electoral, sistema electoral.

FECHA DE RECEPCIÓN: 13.09.2019

FECHA DE ACEPTACIÓN: 19.02.2020 
